ISSN : 2615-1995, E-ISSN : 2615-0654

J. Madani., Vol. 4, No. 2, September 2021 (162 - 175)

C2018 Lembaga Kajian Demokrasi

https://doi.org/10.33753/madani.v4i2.178

\title{
Pengaruh Kompensasi dan Motivasi Terhadap Kinerja Karyawan Pada PT Putra Abadi Jaya Mandiri
}

\author{
Zackharia Rialmi \\ Fakultas Ekonomi Bisnis, Universitas Pembangunan Nasional Veteran Jakarta \\ zac_rialmi@upnvj.ac.id \\ Selvi Sasmanita \\ Fakultas Ekonomi dan Bisnis, Universitas Pamulang \\ selvi.sasmanita@gmail.com
}

\begin{abstract}
Abstrak
Penelitian ini dilakukan untuk menguji pengaruh kompensasi dan motivasi terhadap kinerja karyawan pada PT Putra Abadi Jaya Mandiri. Metode penelitian yang digunakan adalah metode kuantitatif dengan penggunaan data primer dan sekunder. Populasi dan sampel adalah sebanyak 50 responden, yang merupakan karyawan PT Putra Abadi Jaya Mandiri. Hasil penelitian ini adalah kompensasi berpengaruh terhadap peningkatan kinerja sebesar 2,7\%. Uji hipotesis parsial diperoleh thitung $>$ t tabel atau (1,144>2,011), hal ini diperkuat dengan signifikansi $P$ value $<$ Sig. 0,05 atau 0,000 <0,05, sehingga HO diterima dan $\mathrm{H1}$ ditolak artinya tidak terdapat pengaruh positif dan signifikan secara parsial antara kompensasi dengan kinerja karyawan. Motivasi kerja berpengaruh positif dan signifikan terhadap kinerja karyawan sebesar 38,4\%. Uji hipotesis parsial diperoleh t hitung $>t$ tabel atau $(5,470>2,011)$, hal ini diperkuat dengan signifikansi $P$ value $<$ Sig. 0,05 atau 0,000 < 0,05, sehingga $\mathrm{HO}$ ditolak dan $\mathrm{H} 2$ diterima artinya terdapat pengaruh positif dan signifikan secara parsial antara motivasi terhadap kinerja karyawan. Uji hipotesis simultan komunikasi dan motivasi kerja berkontribusi sebesar 42,8\%, Sedangkan sisanya sebesar 57,2\% dipengaruhi oleh faktor lain. Dari uji hipotesis diperoleh $F$ hitung $>$ F tabel atau $(1,308<2,800)$, hal tersebut juga diperkuat dengan signifikansi $(0,000<0,05)$. Dengan demikian $\mathrm{HO}$ diterima $\mathrm{H} 3$ ditolak. Artinya tidak terdapat pengaruh positif dan signifikan secara simultan antara kompensasi dan motivasi terhadap kinerja karyawan pada PT Putra Abadi Jaya Mandiri.
\end{abstract}

Kata Kunci : Kompensasi, Motivias Kerja,, Kinerja Karyawan

\begin{abstract}
This study was conducted to examine the effect of compensation and motivation on employee performance at PT Putra Abadi Jaya Mandiri. The research method used is a quantitative method with the use of primary and secondary data. The population and sample are 50 respondents, who are employees of PT Putra Abadi Jaya Mandiri. The result of this study is that compensation has an effect on increasing performance by $2.7 \%$. Partial hypothesis test obtained tarithmetic $>t$ tabel or (1.144> 2.011), this is reinforced by the significance of $P$ value $<$ Sig. 0.05 or $0.000<0.05$, so that $H 0$ is accepted and $\mathrm{HI}$ is rejected, meaning that there is no positive and partially significant effect between compensation and employee performance. Work motivation has a positive and significant effect on employee performance by $38.4 \%$. Partial hypothesis test obtained tcount $>$ t tabel or (5,470>2,011), this is reinforced by the significance of P value $<$ Sig. 0.05 or $0.000<0.05$, so $\mathrm{HO}$ is rejected and $\mathrm{H} 2$ is accepted, meaning that there is a positive and partially significant influence between motivation on employee performance. Simultaneous hypothesis testing of communication and work motivation contributed $42.8 \%$, while the remaining $57.2 \%$ was influenced by other factors. From the hypothesis test, it was obtained that $F$ arithmetic $>F$ tabel or $(1,308<2,800)$, this was also strengthened by the significance $(0.000$
\end{abstract}


$<0.05)$. Thus $H 0$ is accepted $H 3$ is rejected. This means that there is no simultaneous positive and significant effect between compensation and motivation on employee performance at PT Putra Abadi Jaya Mandiri,

Keywords : Compensation, Work Motivation, Employee Performance

\section{PENDAHULUAN}

Sumber daya manusia (SDM) adalah faktor produksi terpenting yang terdapat di dalam suatu organisasi atau institusi (Rialmi et al., 2020) Produk (barang maupun jasa) yang dihasilkan oleh SDM akan menjadi luaran yang sangat menentukan keberhasilan maupun eksitensi dari suatu organisasi atau institusi. SDM adalah individu yang bekerja pada suatu organisasi, baik institusi maupun perusahaan dan berfungsi sebagai aset yang harus dilatih dan dikembangkan kemampuannya, karyawan dan perusahaan merupakan dua hal yang tidak dapat dipisahkan, karyawan memegang peran utama dalam menjalankan kegiatan perusahaan. Menurut Hidayati (2020, hlm. 4) Perkembangan suatu perusahaan dapat tercapai apabila memiliki kualitas SDM yang baik, karenanya perusahaan dengan kualitas yang baik mampu menjalankan tugas dan fungsi perusahaan sehingga mampu mencapai tujuan yang diharapkan. Setiap perusahaan berusaha meningkatkan serta mengembangkan perusahaan dengan mengadakan berbagai cara yang tersusun dalam program peningkatan kinerja para karyawan. Untuk memperoleh kemajuan dan mencapai tujuan yang telah ditetapkan suatu perusahaan perlu menggerakkan serta memantau karyawannya agar dapat mengembangkan seluruh kemmapuan yang dimilikinya.

Kompensasi menurut Hasibuan dalam (Dwianto et al., 2019) adalah imbalan jasa yang diberikan oleh Organisasi Kepada para karyawan karena karyawan tersebut telah memberikan sumbangan tenaga dan pikiran demi kemajuan Organisasi guna mencapai tujuan yang terlah ditentukan. Menurut Sedarmayanti dalam (Hasibuan, 2019) kompensasi adalah segala sesuatu yang diterima karyawan sebagai balas jasa kerja mereka. Sedangkan menurut (Hasibuan, S.P, 2016) menyatakan, kompensasi adalah semua pendapatan yang berbentuk uang, barang langsung maupun tidak langsung yang diterima oleh karyawan sebagai imbalan atas jasa yang diberikan kepada perusahaan. Motivasi adalah berasal dari kata latin movere yang berarti dorongan, daya penggerak atau kekuatan yang menyebabkan suatu tindakan atau perbuatan. Kata movere, dalam bahasa inggris, sering disepadankan dengan motivation yang berarti pemberian motif, penimbulan motif, atau hal yang menimbulkan dorongan atau keadaan yang menimbulkan dorongan. Seseorang melakukan sesatu tindakan biasanya mempunyai suatu motif Notoadmodjo dalam (Silaen et al., 2021) dan ada maksud dan tujuan tertentu, adanya kebutuhan orang tersebut dan kebanggaan dan kehormatan, serta mungkin limpahan materi (Suwatno \& Priansa, 2014). Pentingnya motivasi kerja bagi suatu perusahaan yakni sebagai faktor pendorong karyawan. Istilah motivating menjadi bentuk usaha untuk mensinkronisasikan tujuan organisasi dan tujuan pribadi masing-masing individu (Syafaruddin, 2015 hlm. 86). Robbins dalam (Fadhil \& Mayowan, 2018) mengatakan bahwa kebutuhan juga menjadi salah satu faktor di dalam terwujudnya motivasi kerja, dikarenakan adanya dorongan mental untuk memenuhi gap antara apa yang dimiliki dan apa yang diharapkan. Oleh Karena itu faktor pendorongnya adalah kebutuhan serta keinginan karyawan tersebut. Kinerja dapat dinilai dari motivasi kerja karyawannya. Salah satu motivasi yang diberikan oleh perusahaan adalah pemberian kompensasi yang sesuai dari kinerja yang dihasilkan dalam menyelesaikan tugas karyawan tersebut.

Menurut Wibowo dalam (Diansyah et al., 2020), kinerja karyawan adalah tanggung jawab setiap individu terhadap pekerjaan, membantu mendefinisikan harapan kerja, mengusahakan kerangka kerja bagi supervisor dan pekerja saling berkomunikasi. Menurut (Sutedjo \& Mangkunegara, 2018) kinerja adalah hasil kerja secara kualitas dan kuantitas yang dicapai oleh seorang karyawan dalam melaksanakan tugasnya sesuai dengan tanggung jawab yang diberikan 
kepadanya. Kinerja sebagai hasil kerja yang dicapai seseorang secara kualitas dan kuantitas harus dipantau secara terus menerus perkembangannya, pemantauan akan memberikan informasi apakah kinerja karyawan telah sesuai dengan harapan organisasi. Menurut Bastian dalam (Komara Eka Putri \& Basri, 2014) kinerja adalah gambaran pencapaian pelaksanaan suatu kegiatan/program/ kebijaksanaan dalam mewujudkan sasaran, tujuan, misi, dan visi organisasi. Pengukuran kinerja menurut (Mulyadi \& Setiawan, 2007:359) adalah penentuan secara periodik efektivitas operasional suatu organisasi, bagian organisasi, dan personilnya, berdasarkan sasaran strategik, standar, dan kriteria yang telah ditetapkan sebelumnya.

PT Putra Abadi Jaya Mandiri adalah perusahaan yang telah berdiri selama 17 (tujuh belas) tahun, sebuah perusahaan swasta dan menjadi salah satu pelaku bisnis yang turut serta berpartisipasi, perusahaan ini bergerak dibidang Contactor dan suplyer yang melakukan kontrak kerja dengan orang atau pemerintah untuk memasok barang atau menyelesaikan jasa tertentu. Bidang pekerjaanya ini meliputi pembangunan gedung, instalasi listrik, dan penyediaan ribuan generator. PT Putra Abadi Jaya Mandiri sendiri yaitu perusahaan swasta yang bekerja sama dengan peusahaan BUMN atau pemerintahan, Penilaian evaluasi kerja merupakan salah satu upaya untuk mengetahui kondisi motivasi dan capaian kerja dalam organisasi, sehingga dapat diketahui dengan pasti apakah pencapaian hasil, kemajuan dan kendala yang dijumpai dalam pelaksanaan program dan kegiatan dapat dinilai dan dipelajari (lesson learned) untuk perbaikan di masa mendatang.

Berdasarkan beberapa faktor yang dapat mempengaruhi kinerja karyawan, maka penulis tertarik untuk melakukan penelitian yang berjudul "Pengaruh Kompensasi dan Motivasi Terhadap Kinerja Karyawan Pada PT Putra Abadi Jaya Mandiri”

\section{METODE}

Penelitian ini dilakukan dengan metode penelitian kuantitatif yang diolah dengan aplikasi statistik. (Sugiyono \& Kuantitatif, 2009) mengatakan Tempat penelitian adalah sasaran ilmiah untuk mendapatkan data dengan tujuan dan kegunaan tertentu tentang sesuatu hal yang objektif. Penelitian ini dilakukan dengan metode penelitian kuantitatif dan diolah dengan aplikasi statistik. Dilaksanakan di PT Putra Abadi Jaya Mandiri yang berlokasi di Jl. Otista Raya No. 57, Cimanggis - Ciputat, Tangerang Selatan, Banten. Penentuan sampel jenuh dilaksanakan kepada 50 responden dari keseluruhan populasi yakni seluruh karyawan. Uji data dilaksanakan dengan uji instrumen, uji korelasi, uji regresi linier sederhana yang dilaksanakan dalam penelitian ini adalah uji instumen, uji korelasi, uji regresi linier sederhana, uji koefisien determiasi dan uji hipotesis.

\section{HASIL}

\section{Deskripsi Responden}

\section{Karakteristik Responden}

Responden dalam penelitian ini adalah 50 karyawan PT Putra Abadi Jaya Mandiri. Responden dibagi kedalam karakteristik berdasarakna berdasarkan jenis kelamin, usia dan tingkat pendidikan sebagai berikut:

a. Berdasarkan Jenis Kelamin

Tabel 1. Karakteristik responden berdasarkan jenis kelamin

\begin{tabular}{|c|c|c|}
\hline Keterangan & Jumlah & Persentase \\
\hline \multicolumn{3}{|c|}{ Jenis Kelamin } \\
\hline Laki-laki & 36 & $72 \%$ \\
\hline Perempuan & 14 & $28 \%$ \\
\hline Total & 50 & $100 \%$ \\
\hline
\end{tabular}

Sumber: Data primer yang diolah, 2020

Pada tabel 1 menunjukan bahwa responden didominasi oleh karyawan berjenis kelamin lakilaki yakni sebanyak 36 orang atau sebesar $72 \%$ dan karyawan dengan jenis kelamin perempuan sebanyak 14 orang atau sebesar $28 \%$.

\section{b. Berdasarkan Usia Responden}

Tabel 2. Responden berdasarkan usia

\begin{tabular}{lll}
\hline \multicolumn{1}{c}{ Keterangan } & \multicolumn{1}{c}{ Jumlah } & Persentase \\
\hline$<25$ Tahun & 10 & $20 \%$ \\
26-35 Tahun & 20 & $40 \%$ \\
>36 Tahun & 20 & $40 \%$ \\
Total & 50 & $100 \%$ \\
\hline
\end{tabular}

Sumber: Data primer yang diolah, 2020 
Pada tabel 2 menunjukan bahwa responden yang paling banyak adalah karyawan yang berusia 26-35 dengan jumlah responden sebanyak 20 responden atau $40 \%$, kemudian yang berusia 36 tahun dengan jumlah responden atau $40 \%$ dan paling terendah adalah responden dengan usia dibawah 25 tahun dengan jumlah responden 10 responden atau $20 \%$.

c. Berdasarkan Pendidikan Responden

Tabel 3. Respinden Berdasarkan Pendidikan

\begin{tabular}{lll}
\hline Keterangan & Jumlah & Persentase \\
\hline SMA & 38 & $76 \%$ \\
D3 & 9 & $18 \%$ \\
S1 & 3 & $6 \%$ \\
Total & 50 & $100 \%$ \\
\hline
\end{tabular}

Sumber: Data primer yang diolah, 2020
Pada tabel 3 menunjukan bahwa responden yang paling banyak adalah yang berpendidikan SMA dengan jumlah responden masingmasing 38 responden atau $76 \%$, kemudian yang berpendidikan D3 mencapai 9 responden atau $18 \%$, dan yang berpendidikan S1 jumlah respondennya 3 responden atau 6\%.'

\section{Uji Validitas}

Berdasarkan tabel 4, nilai semua item pernyataan variabel kompensasi (X1) diperoleh nilai Cronbatch Alpha lebih besar dari 0,300, dengan demikian maka semua item kuesioner dinyatakan valid. Untuk itu kuesioner yang digunakan layak untuk diolah sebagai data penelitian.

Berdasarkan tabel 5, hasil uji validitas instrument variabel motivasi (X2) diperoleh nilai

Tabel 4. Uji validitas pernyataan variabel kompensasi (X1)

\begin{tabular}{|c|c|c|c|c|}
\hline No & Pernyataan & $\begin{array}{l}\text { Cronbatch } \\
\text { Alfa }\end{array}$ & $\begin{array}{c}\text { Standar } \\
\text { Cronbatch } \\
\text { Alpa } \\
\end{array}$ & Keputusan \\
\hline 1 & $\begin{array}{l}\text { Perusahaaan tempat saya bekerja, dalam memberikan } \\
\text { gaji setiap bulan telah mampu memenuhi kebutuhan } \\
\text { sehari-hari karyawan }\end{array}$ & 0,749 & 0,300 & Valid \\
\hline 2 & $\begin{array}{l}\text { Gaji yang saya terima sesuai dengan beban kerja } \\
\text { yang ditanggung }\end{array}$ & 0,749 & 0,300 & Valid \\
\hline 3 & $\begin{array}{l}\text { Upah ynag diterima sesuai dengan tingkat kesulitan } \\
\text { pekerjaan }\end{array}$ & 0,749 & 0,300 & Valid \\
\hline 4 & Upah sesuai dengan jam kerja dan kuantitas produksi & 0,749 & 0,300 & Valid \\
\hline 5 & $\begin{array}{l}\text { Insentif yang diberikan perusahaan tempat saya } \\
\text { bekerja selama ini dapat meningkat semangat kerja } \\
\text { dalam bekerja }\end{array}$ & 0,749 & 0,300 & Valid \\
\hline 6 & $\begin{array}{l}\text { Insentif yang diterima dapat meningkatkan semangat } \\
\text { kerja }\end{array}$ & 0,749 & 0,300 & Valid \\
\hline 7 & $\begin{array}{l}\text { Fasilitas penunjang kesehatan dapat membuat saya } \\
\text { nyaman dalam bekerja }\end{array}$ & 0,749 & 0,300 & Valid \\
\hline 8 & $\begin{array}{l}\text { Fasilitas K3 di lokasi bekerja dapat membuat diri } \\
\text { saya aman bekerja }\end{array}$ & 0,749 & 0,300 & Valid \\
\hline 9 & $\begin{array}{l}\text { Tunjangan yang diberikan perusahaan memenuhi ke- } \\
\text { butuhan saya dan keluarga }\end{array}$ & 0,749 & 0,300 & Valid \\
\hline 10 & Tunjagan yang diberikan sesuai dengan harapan saya & 0,749 & 0,300 & Valid \\
\hline
\end{tabular}

Sumber: Output SPSS yang diolah, 2020 
Tabel 5. Uji validitas pernyataan variabel motivasi (X2)

\begin{tabular}{|c|c|c|c|c|}
\hline No & Pernyataan & $\begin{array}{l}\text { Cronbatch } \\
\text { Alfa }\end{array}$ & $\begin{array}{c}\text { Standar } \\
\text { Cronbatch } \\
\text { Alpa }\end{array}$ & Keputusan \\
\hline 1 & $\begin{array}{l}\text { Gaji perusahaan telah sesuai dengan ketentuan yang } \\
\text { berlaku }\end{array}$ & 0,744 & 0,300 & Valid \\
\hline 2 & $\begin{array}{l}\text { Gaji yang diberikan perusahaan kepada karyawan, } \\
\text { membuat karyawan termotivasi untuk bekerja }\end{array}$ & 0,744 & 0,300 & Valid \\
\hline 3 & $\begin{array}{l}\text { Keamanan dilingkungan kerja sudah dikelola dengan } \\
\text { baik }\end{array}$ & 0,744 & 0,300 & Valid \\
\hline 4 & $\begin{array}{l}\text { Fasilitas ruang kerja yang digunakan nyaman dan } \\
\text { bersih }\end{array}$ & 0,744 & 0,300 & Valid \\
\hline 5 & $\begin{array}{l}\text { Hubungan kerja dengan atasan atau pimpinan terjalin } \\
\text { dengan baik }\end{array}$ & 0,744 & 0,300 & Valid \\
\hline 6 & $\begin{array}{l}\text { Hubungan kerja sesama rekan kerja di perusahaann } \\
\text { ini terjalin dengan harmonis }\end{array}$ & 0,744 & 0,300 & Valid \\
\hline 7 & $\begin{array}{l}\text { Perusahaan memberikan kesempatan bagi karyawan } \\
\text { untuk mengembangkan potensi yang ada pada dirin- } \\
\text { ya untuk lebih maju }\end{array}$ & 0,744 & 0,300 & Valid \\
\hline 8 & $\begin{array}{l}\text { Selama ini perusahaan mengakui dan menghargai ha- } \\
\text { sil kerja saya }\end{array}$ & 0,744 & 0,300 & Valid \\
\hline 9 & $\begin{array}{l}\text { Perusahaan memberikan kesempatan bagi karyawan } \\
\text { untuk mengembangkan potensi yang ada pada dirin- } \\
\text { ya untuk lebih maju }\end{array}$ & 0,744 & 0,300 & Valid \\
\hline 10 & $\begin{array}{l}\text { Motivasi yang diberikan oleh atasan membuat saya } \\
\text { lebih disiplin dalam bekerja }\end{array}$ & 0,744 & 0,300 & Valid \\
\hline
\end{tabular}

Sumber: Output SPSS yang diolah, 2020

Tabel 6. Uji validitas pernyataan variabel kinerja (Y)

\begin{tabular}{|c|c|c|c|c|}
\hline No & Pernyataan & $\begin{array}{l}\text { Cronbatch } \\
\text { Alfa }\end{array}$ & $\begin{array}{c}\text { Standar } \\
\text { Cronbatch } \\
\text { Alpa }\end{array}$ & Keputusan \\
\hline 1 & Saya mengetahui tujuan dan kewajiban dalam bekerja & 0,738 & 0,300 & Valid \\
\hline 2 & Saya mengetahui satndar aturan yang ditentukan perusahaan & 0,738 & 0,300 & Valid \\
\hline 3 & $\begin{array}{l}\text { Saya mengetahui tingkat umpan balik sesuai pekrjaan } \\
\text { yang diberikan perusahaan }\end{array}$ & 0,738 & 0,300 & Valid \\
\hline 4 & $\begin{array}{l}\text { Saya dalam bekreja selau mengutamakan alat atau sa- } \\
\text { rana yang diberikan }\end{array}$ & 0,738 & 0,300 & Valid \\
\hline 5 & $\begin{array}{l}\text { Memiliki tingkat kompetensi yang tinggi dan beru- } \\
\text { saha untuk mengikuti perkembangan yang ada }\end{array}$ & 0,738 & 0,300 & Valid \\
\hline 6 & Saya memiliki motif yang diberikan perusahaan & 0,738 & 0,300 & Valid \\
\hline 7 & Saya mengetahui dalam memajukan karyawan & 0,738 & 0,300 & \\
\hline 8 & $\begin{array}{l}\text { Memiliki pengetahuan yang luas yang dapat mem- } \\
\text { bantu orang lain dalam pengambilan keputusan }\end{array}$ & 0,738 & 0,300 & Valid \\
\hline 9 & $\begin{array}{l}\text { Memiliki kepercayaan diri dan kemampuan yang } \\
\text { tinggi dalam membuat keputusan yang baik }\end{array}$ & 0,738 & 0,300 & Valid \\
\hline 10 & $\begin{array}{l}\text { Mampu memilih dan melihat dari sudut pandang } \\
\text { yang berbeda dengan orang lain }\end{array}$ & 0,738 & 0,300 & Valid \\
\hline
\end{tabular}

Sumber: Output SPSS yang diolah, 2020 
Tabel 7. Hasil uji reliabilitas variabel independen dan dependen

\begin{tabular}{llccc}
\hline No. & Variabel & $\begin{array}{c}\text { Cronbach's } \\
\text { Alpha }\end{array}$ & Nilai r tabel & Keputusan \\
\hline 1 & Kompensasi & 0,749 & 0,600 & Reliabel \\
2 & Motivasi & 0,744 & 0,600 & Reliabel \\
3 & Kinerja & 0,738 & 0,600 & Reliabel \\
\hline
\end{tabular}

Sumber: Output SPSS yang diolah, 2020

PEMBAHASAN

Variabel Kompensasi (X1)

Tabel 8. Distribusi jawaban responden variabel kompensasi (X1)

\begin{tabular}{|c|c|c|c|c|c|c|c|c|c|}
\hline \multirow[t]{2}{*}{ No } & \multirow[t]{2}{*}{ Pernyataan } & \multicolumn{5}{|c|}{ Alternatif Jawaban } & \multirow[t]{2}{*}{ Jumlah } & \multirow[t]{2}{*}{ Skor } & \multirow[t]{2}{*}{ Ket } \\
\hline & & SS & $\mathbf{S}$ & KS & TS & STS & & & \\
\hline 1 & $\begin{array}{l}\text { Perusahaaan tempat saya bekerja, } \\
\text { dalam memberikan gaji setiap } \\
\text { bulan telah mampu memenuhi } \\
\text { kebutuhan sehari-hari karyawan }\end{array}$ & 7 & 33 & 7 & 3 & 0 & 50 & 3,88 & Baik \\
\hline 2 & $\begin{array}{l}\text { Gaji yang saya terima sesuai } \\
\text { dengan beban kerja yang } \\
\text { ditanggung }\end{array}$ & 6 & 35 & 6 & 1 & 2 & 50 & 3,84 & Baik \\
\hline 3 & $\begin{array}{l}\text { Upah ynag diterima sesuai dengan } \\
\text { tingkat kesulitan pekerjaan }\end{array}$ & 3 & 37 & 7 & 2 & 1 & 50 & 3,78 & Baik \\
\hline 4 & $\begin{array}{l}\text { Upah sesuai dengan jam kerja dan } \\
\text { kuantitas produksi }\end{array}$ & 7 & 34 & 5 & 1 & 3 & 50 & 3,82 & Baik \\
\hline 5 & $\begin{array}{l}\text { Insentif yang diberikan perusahaan } \\
\text { tempat saya bekerja selama ini } \\
\text { dapat meningkat semangat kerja } \\
\text { dalam bekerja }\end{array}$ & 10 & 23 & 8 & 5 & 4 & 50 & 3,7 & Baik \\
\hline 6 & $\begin{array}{l}\text { Insentif yang diterima dapat } \\
\text { meningkatkan semangat kerja }\end{array}$ & 10 & 29 & 6 & 5 & 0 & 50 & 3,88 & Baik \\
\hline 7 & $\begin{array}{l}\text { Fasilitas penunjang kesehatan } \\
\text { dapat membuat saya nyaman } \\
\text { dalam bekerja }\end{array}$ & 11 & 29 & 6 & 4 & 0 & 50 & 3,94 & Baik \\
\hline 8 & $\begin{array}{l}\text { Fasilitas K3 di lokasi bekerja dapat } \\
\text { membuat diri saya aman bekerja }\end{array}$ & 11 & 29 & 6 & 5 & 0 & 51 & 3,96 & Baik \\
\hline 9 & $\begin{array}{l}\text { Tunjangan yang diberikan } \\
\text { perusahaan memenuhi kebutuhan } \\
\text { saya dan keluarga }\end{array}$ & 5 & 27 & 12 & 5 & 1 & 50 & 3,6 & Baik \\
\hline 10 & $\begin{array}{l}\text { Tunjagan yang diberikan sesuai } \\
\text { dengan harapan saya }\end{array}$ & 1 & 24 & 15 & 7 & 3 & 50 & 3,26 & Baik \\
\hline Jum & & 66 & 309 & 74 & 37 & 14 & 500 & Rata2 & \\
\hline Per & entase & $13,2 \%$ & $61,8 \%$ & $14,8 \%$ & $7,4 \%$ & $2,8 \%$ & 100 & 3,766 & Baik \\
\hline
\end{tabular}

Sumber: Output SPSS yang diolah, 2020 
Variabel Kompensasi (X2)

Tabel 9. Distribusi jawaban responden kuesioner variabel motivasi (X2)

\begin{tabular}{|c|c|c|c|c|c|c|c|c|c|}
\hline \multirow[t]{2}{*}{ No } & \multirow[t]{2}{*}{ Pernyataan } & \multicolumn{5}{|c|}{ Alternatif Jawaban } & \multirow[t]{2}{*}{ Total } & \multirow[t]{2}{*}{ Skor } & \multirow[t]{2}{*}{ Ket } \\
\hline & & SS & $\mathbf{S}$ & KS & TS & STS & & & \\
\hline 1 & $\begin{array}{l}\text { Gaji perusahaan telah sesuai } \\
\text { dengan ketentuan yang berlaku }\end{array}$ & 4 & 35 & 5 & 5 & 1 & 50 & 3,72 & Baik \\
\hline 2 & $\begin{array}{l}\text { Gaji yang diberikan perusahaan } \\
\text { kepada karyawan, membuat } \\
\text { karyawan termotivasi untuk } \\
\text { bekerja }\end{array}$ & 4 & 33 & 10 & 2 & 1 & 50 & 3,74 & Baik \\
\hline 3 & $\begin{array}{l}\text { Keamanan dilingkungan kerja } \\
\text { sudah dikelola dengan baik }\end{array}$ & 3 & 42 & 3 & 1 & 1 & 50 & 3,9 & Baik \\
\hline \multirow[t]{2}{*}{4} & $\begin{array}{l}\text { Fasilitas ruang kerja yang } \\
\text { digunakan nyaman dan bersih }\end{array}$ & & & & & & & & \\
\hline & 7 & 40 & 1 & 2 & 0 & 50 & 4,04 & Baik & \\
\hline 5 & $\begin{array}{l}\text { Hubungan kerja dengan atasan } \\
\text { atau pimpinan terjalin dengan } \\
\text { baik }\end{array}$ & 6 & 39 & 4 & 1 & 0 & 50 & 4,0 & Baik \\
\hline 6 & $\begin{array}{l}\text { Hubungan kerja sesama rekan } \\
\text { kerja di perusahaann ini terjalin } \\
\text { dengan harmonis }\end{array}$ & 8 & 38 & 2 & 1 & 1 & 50 & 4,02 & Baik \\
\hline 7 & $\begin{array}{l}\text { Perusahaan memberikan } \\
\text { kesempatan bagi karyawan untuk } \\
\text { mengembangkan potensi yang ada } \\
\text { pada dirinya untuk lebih maju }\end{array}$ & 11 & 33 & 3 & 2 & 1 & 50 & 4,68 & Baik \\
\hline 8 & $\begin{array}{l}\text { Selama ini perusahaan mengakui } \\
\text { dan menghargai hasil kerja saya }\end{array}$ & 2 & 40 & 6 & 0 & 2 & 50 & 3,8 & Baik \\
\hline 9 & $\begin{array}{l}\text { Perusahaan memberikan } \\
\text { kesempatan bagi karyawan untuk } \\
\text { mengembangkan potensi yang } \\
\text { ada pada dirinya untuk lebih maju }\end{array}$ & 7 & 36 & 5 & 1 & 1 & 50 & 3,94 & Baik \\
\hline 10 & $\begin{array}{l}\text { Motivasi yang diberikan oleh } \\
\text { atasan membuat saya lebih } \\
\text { disiplin dalam bekerja }\end{array}$ & 8 & 36 & 3 & 1 & 2 & 50 & 3,94 & Baik \\
\hline \multicolumn{2}{|c|}{ Jumlah } & 60 & 372 & 42 & 16 & 10 & 500 & Rata2 & \\
\hline \multicolumn{2}{|c|}{ Persentase } & $12,0 \%$ & $74,4 \%$ & 8,4 & $3,2 \%$ & $2,0 \%$ & 100 & 3,978 & Baik \\
\hline
\end{tabular}

Sumber: Output SPSS yang diolah, 2020

Cronbatch Alfa lebih besar dari 0,300 dengan demikian maka semua item kuesioner dinyatakan valid. Untuk itu kuesioner yang digunakan layak untuk diolah sebagai data penelitian.

Berdasarkan tabel 6, nilai semua item pernyataan variabel kinerja (Y) diperoleh nilai Cronbatch Alfa lebih besar dari 0,300 dengan demikian maka semua item kuesioner dinyatakan valid. Untuk itu kuesioner yang digunakan layak untuk diolah sebagai data penelitian.

Berdasarkan tabel 7, diketahui bahwa semua item pernyataan variabel kompensasi (X1) motivasi (X2) dan kinerja (Y) dinyatakan reliabel, hal itu dibuktikan dengan masing-masing variabel memiliki nilai Coeficien Alpha lebih besar dari Chronbatch Alpha 0,600.

Berdasarkan tabel 8, tanggapan responden atas pernyataan pada variabel kompensasi diperoleh 
Variabel Kompensasi (Y)

Tabel 10. Distribusi jawaban kuesioner variabel kinerja karyawan $(\mathrm{Y})$

\begin{tabular}{|c|c|c|c|c|c|c|c|c|c|}
\hline \multirow[t]{2}{*}{ No } & \multirow[t]{2}{*}{ Pernyataan } & \multicolumn{5}{|c|}{ Alternatif Jawaban } & \multirow[t]{2}{*}{ Total } & \multirow[t]{2}{*}{ Skor } & \multirow[t]{2}{*}{ Ket } \\
\hline & & SS & $\mathbf{S}$ & KS & TS & STS & & & \\
\hline 1 & $\begin{array}{l}\text { Saya mengetahui tujuan dan } \\
\text { kewajiban dalam bekerja }\end{array}$ & 9 & 39 & 1 & 1 & 0 & 50 & 4,12 & Baik \\
\hline 2 & $\begin{array}{l}\text { Saya mengetahui satndar aturan } \\
\text { yang ditentukan perusahaan }\end{array}$ & 7 & 41 & 2 & 0 & 0 & 50 & 4,1 & Baik \\
\hline 3 & $\begin{array}{l}\text { Saya mengetahui tingkat umpan } \\
\text { balik sesuai pekrjaan yang } \\
\text { diberikan perusahaan }\end{array}$ & 4 & 39 & 5 & 2 & 0 & 50 & 3,9 & Baik \\
\hline 4 & $\begin{array}{l}\text { Saya dalam bekreja selau } \\
\text { mengutamakan alat atau sarana } \\
\text { yang diberikan }\end{array}$ & 8 & 38 & 3 & 1 & 0 & 50 & 4,04 & Baik \\
\hline 5 & $\begin{array}{l}\text { Memiliki tingkat kompetensi } \\
\text { yang tinggi dan berusaha untuk } \\
\text { mengikuti perkembangan yang } \\
\text { ada }\end{array}$ & 13 & 33 & 4 & 0 & 0 & 50 & 4,18 & Baik \\
\hline 6 & $\begin{array}{l}\text { Saya memiliki motif yang } \\
\text { diberikan perusahaan }\end{array}$ & 4 & 36 & 5 & 3 & 2 & 50 & 3,74 & Baik \\
\hline 7 & $\begin{array}{l}\text { Saya mengetahui dalam } \\
\text { memajukan karyawan }\end{array}$ & 7 & 41 & 2 & 0 & 0 & 50 & 4,1 & Baik \\
\hline 8 & $\begin{array}{l}\text { Memiliki pengetahuan yang luas } \\
\text { yang dapat membantu orang lain } \\
\text { dalam pengambilan keputusan }\end{array}$ & 3 & 43 & 3 & 1 & 0 & 50 & 3,96 & Baik \\
\hline 9 & $\begin{array}{l}\text { Memiliki kepercayaan diri dan } \\
\text { kemampuan yang tinggi dalam } \\
\text { membuat keputusan yang baik }\end{array}$ & 3 & 42 & 3 & 2 & 0 & 50 & 3,92 & Baik \\
\hline 10 & $\begin{array}{l}\text { Mampu memilih dan melihat } \\
\text { dari sudut pandang yang berbeda } \\
\text { dengan orang lain }\end{array}$ & 3 & 43 & 2 & 0 & 2 & 50 & 3,9 & Baik \\
\hline Jun & & 61 & 395 & 30 & 10 & 4 & 500 & Rata2 & \\
\hline Per & entase & $12,2 \%$ & $79,0 \%$ & $6,0 \%$ & $2,0 \%$ & $0,8 \%$ & 100 & 3,998 & Baik \\
\hline
\end{tabular}

Sumber: Output SPSS yang diolah, 2020

rata-rata skor 3,766 termasuk pada rentang skala 3,40-4,19 dengan kriteria baik. Responden yang menjawab sangat setuju dan setuju sebesar $75,02 \%$ dan responden yang menjawab kurang setuju kurang setuju dan sangat tidak setuju mencapai $25 \%$.

Berdasarkan tabel 9, tanggapan responden atas pernyataan pada variabel kompensasi diperoleh rata-rata skor 3,988 termasuk pada rentang skala 3,40-4,19 dengan kriteria baik. Responden yang menjawab sangat setuju dan setuju sebesar $86,64 \%$ dan responden yang menjawab kurang setuju kurang setuju dan sangat tidak setuju mencapai $13.0 \%$.
Berdasarkan tabel 10, tanggapan responden pada varibael kinerja diperoleh rata-rata skor 3,998 termasuk pada rentang skala 3,404,19 dengan kriteria baik. Responden yang menjawab sangat setuju dan setuju sebesar 91,2\% dan responden yang menjawab kurang setuju tidak setuju dan sangat tidak setuju mencapai $8,8 \%$.

\section{Persamaan Regresi Linier}

Uji regresi linear berganda dikamsud untuk mengetahui seberapa besar pengaruh variabel $\mathrm{X} 1$ dan $\mathrm{X} 2$ terhadap $\mathrm{Y}$ yang dalam penelitian ini adalah Kompensasi (X1) dan motivasi (X2) terhadap kinerja karyawan (Y) berikut hasil 
Tabel 11. Hasil pengujian regresi linier sederhana variabel kompensasi (X1) terkadap kinerja karyawan (Y)

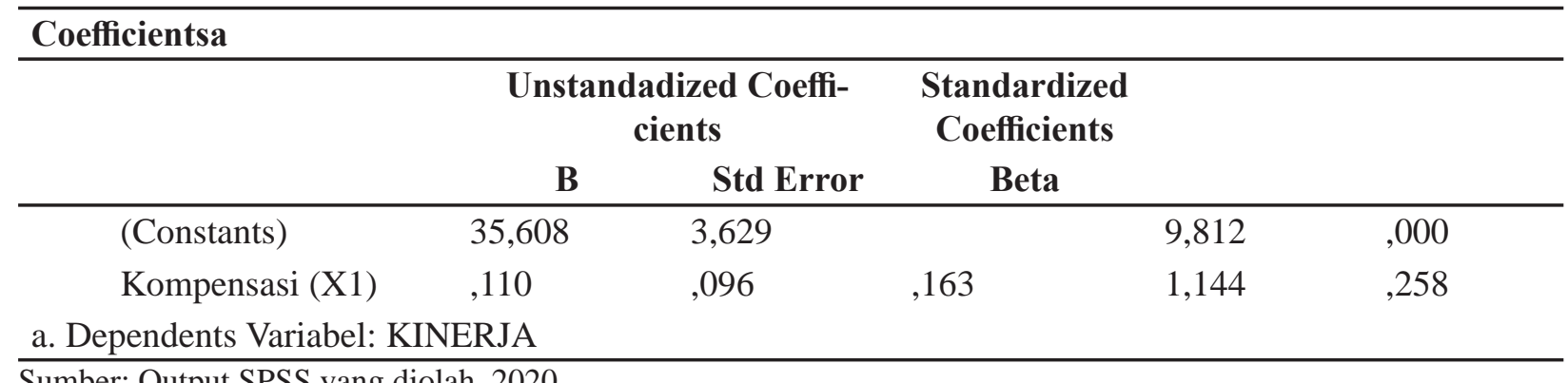

Sumber: Output SPSS yang diolah, 2020

Tabel 12. Hasil pengujian regresi linier sederhana variabel motivasi (X2) terhadap kinerja karyawan (Y)

Coefficientsa

\begin{tabular}{cccccc}
\hline \multicolumn{7}{c}{ Unstandadized Coefficients } & \multicolumn{2}{c}{$\begin{array}{c}\text { Standardized } \\
\text { Coefficients } \\
\text { Beta }\end{array}$} \\
& B & Std Error & \multicolumn{2}{c}{} & \\
\hline (Constants) & 19,167 & 3,778 & & 5,074 &, 000 \\
Motivasi (X2) &, 525 &, 096 &, 620 & 5,470 & .000 \\
a. Dependents Variabel: KINERJA & & & & \\
\hline
\end{tabular}

Sumber: Output SPSS yang diolah, 2020

Tabel 13. Hasil pengujian regresi berganda variabel kompensasi (X1) dan motivasi (X2) terhadap kinerja karyawan (Y)

\begin{tabular}{llllll}
\hline Coefficientsa & \multicolumn{7}{c}{ Unstandadized Coefficients } & $\begin{array}{c}\text { Standardized } \\
\text { Coefficients } \\
\text { Beta }\end{array}$ \\
& \multicolumn{7}{c}{ B } & Std Error & 3,796 & & 5,519 &, 000 \\
\hline (Constant) & 20,952 & 3,089 &,- 250 & $-1,902$ &, 063 \\
Kompensasi (X1) &,- 169 &, 089 & 5,744 &, 000 \\
Motivasi Kerja (X2) &, 641 &, 112 &, 757 & & \\
a. Dependent Variabel: Kinerja Karyawan (Y) & & & &
\end{tabular}

Sumber: Data Primer diolah

olahan dan regresi dengan aplikasi SPSS versi 24 yang dapat dilihat pada tabel 11.

Berdasarkan hasil perhitungan regresi pada tabel 11, maka dapat diperoleh persamaan regresi $\mathrm{Y}=35,608=0,110 \mathrm{X} 1$. Dari persamaan di atas maka dapat disimpulkan sebagai berikut:

1. Nilai konstanta sebesar 35,608 diartikan bahwa jika variabel kompensasi (X1) tidak ada maka telah terdapat nilai kinerja karyawan (Y) sebesar 15,791 point.

2. Nilai koefisien regresi kompensasi (X1) sebesar 0,110 diartikan apabila konstanta tetap dan tidak ada perubahan pada variabel motivasi (X2), maka setiap perubahan I unit pada variabel kompensasi (X1) akan mengakibatkan terjadinya perubahan pada kinerja karyawan (Y) sebesar 0,110 point.

Berdasarkan hasil perhitungan regresi pada tabel 12, maka dapat diperoleh persamaan regsesi di atas maka dapat sisimpulkan sebagai berikut:

1. Nilai konstanta sebesar 19,167 diartikan bahwa jika variabel motivasi (X2) tidak ada, maka telah terdapat nilai kinerja kerja karyawan (Y) sebesar 19,167 point.

2. Nilai koefisien regresi motivasi (X2) sebesar 0,525 diartikan apabila konstanta tetap dan tidak ada perubahan pada variabel Kompensai (X1), maka setiap perubahan 1unit pada 
variabel motivasi (X2) akan mengakibatkan tejadinya perubahan pada kinerja karyawan (Y) sebesar 0,525 point.

Berdasarkan hasil analisis perhitungan regresi pada tabel di atas, maka dapat diperoleh persamaan regresi $\mathrm{Y}=20,952+0,169 \mathrm{X} 1+$ 0,641X2 Dari persamaan diatas maka dapat disimpulkan sebagai berikut:

1. Nilai konstanta sebesar 20,952 diartikan bahwa jika variabel Kompensasi (X1) dan Motivasi (X2) tidak ada maka telah terdapat nilai Kinerja karyawan (Y) sebesar 20,952 point.

2. Nilai X1 0,169 diartikan apabila konstanta tetap dan tidak ada perubahan pada variabel Motivasi (X2), maka setiap perubahan 1 unit pada variabel Kompensasi (X1) akan mengakibatkan terjadinya perubahan pada Kinerja karyawan (Y) sebesar 0,169 point.
3. Nilai X2 0,641diartikan apabila konstanta tetap dan tidak ada perubahan pada variabel Kompensasi (X1), maka setiap perubahan 1 unit pada variabel Motivasi (X2) akan mengakibatkan terjadinya perubahan pada Kinerja karyawan $(\mathrm{Y})$ sebesar 0,641 point.

\section{Uji Koefiisen Korelasi}

Analisis koefisien korelasi dimaksud untuk mengetahui tingkat kekuatan hubungan antara variabel independen terhadap variabel dependen. Hasil pengolahan sebagai berikut:

Berdasarkan pada hasil pengujian tabel 14, diperoleh nilai $\mathrm{R}$ (koefisien korelasi) sebesar 0,163 artinya kedua variabel tidak memiliki hubungan atau pengaruh yang kuat.

Berdasarkan hasil pengujian pada tabel 15 , diperoleh nilai $\mathrm{R}$ (koefisien korelasi) sebesar 0,620 artinya kedua variabel mempunyai tingkat pengaruh atau hubungan yang kuat.

Tabel 14. Hasil analisis koefisien korelasi secara parsial antara kompensasi (X1)

Terhadap kinerja karyawan (Y)

Correlations $^{\mathrm{b}}$

\begin{tabular}{llll}
\hline & & Kompensasi & Kinerja Karyawan(Y) \\
\hline Person Correlation & 1 & $.163^{* *}$ \\
Sig. (2-tailed) & &, 258 \\
Pearson Correlation & $.163^{* *}$ & 1 \\
Sig. (2-tailed) & .258 & \\
\hline
\end{tabular}

Sumber: Output SPSS yang diolah, 2020

Tabel 15. Hasil analisis koefisien korelasi secara parsial antara motivasi (X2) terhadap kinerja karyawan (Y) Correlations $^{\mathrm{b}}$

\begin{tabular}{llll}
\hline & & Kompensasi & Kinerja Karyawan(Y) \\
\hline Person Correlation & 1 & $.620^{* *}$ \\
Sig. (2-tailed) & &, 000 \\
Pearson Correlation & $.620^{* *}$ & 1 \\
Sig. (2-tailed) & .000 & \\
\hline
\end{tabular}

Sumber: Output SPSS yang diolah, 2020

Tabel 16. Hasil analisis koefisien korelasi secara simultan antara kompensasi (X1) dan motivasi (X2) terhadap kinerja karyawan (Y)

\begin{tabular}{lllll}
\hline & \multicolumn{5}{c}{ Model Sumery } \\
\hline Model & R & R Square & $\begin{array}{c}\text { Adjusted R } \\
\text { Square }\end{array}$ & Std. Error of the Estimate \\
\hline 1 &, 654 &, 428 & 404 & 269,339 \\
\hline
\end{tabular}

a. $\quad$ Predictors: (Constant), Motivasi (X2), Kompensasi (X1)

Sumber: Output SPSS yang diolah, 2020 
Berdasarkan pada hasil pengujian pada tabel 16, diperoleh nilai $\mathrm{R}$ (koefisien korelasi) sebesar 0,654 artinya variabel kompensasi (X1) dan motivasi (X2) mempunyai tingkat pengaruh atau hubungan yang kuat terhadap kinerja karyawan (Y).

\section{Koefisien Determinasi}

\section{Analisis Koefisien Determinan (R Square)}

Analisis koefisien determian dimaksudkan untuk mengetahui persentase kekuatan hubungan antara variabel independen terhadapa variabel dependen baik secara parsial maupun simultan, dalam penelitian ini adalah variabel kompensasi (X1) dan motivasi (X2) terhadapa kinerja karyawan (Y). Berikut ini hasil perhitungan koefisien determinan yang diolah dengan program SPSS versi 24 sebagai berikut.

Berdasarkan hasil pada pengujian tabel 17 , diperoleh nilai R-Square (koefisien determinan) sebesar 0,027 maka dapat disimpulkan bahwa variabel kompensasi (X1) berpengaruh terhadap variabel kinerja karyawan (Y) sebesar 2,7\% sedangkan 97,3\% dipengaruhi oleh faktor lain.

Berdasarkan hasil pengujian tabel 18, diperoleh nilai R-Square (koefisien korelasi) sebesar 0,384 maka dapat disimpulkan bahwa variabel motivasi (X2) berpengaruh sebesar $38,4 \%$ sedangkan $61,6 \%$ dipengaruhi faktor lain.

Berdasarkan hasil pada pengujian kedua variabel di atas, diperoleh nilai R-Square sebesar 0,428 maka kesimpulan yang bisa diambil dari kedua variabel kompensasi (X1) dan motivasi (X2) diperoleh nilai sebesar $42,8 \%$ sedangkan sisanya sebesr $57,2 \%$ dpengaruhi oleh factor lain yang tidak dilakukan penelitian.

\section{Pengujian Hipotesis}

\section{Pengujian Hipotesis Secara Parsial (Uji t)}

Berdasarkan pada hasil tabel pengujian 20 diperoleh $\mathrm{t}$ hitung $<\mathrm{t}$ tabel $(1,144<2,011) \mathrm{Hal}$ tersebut juga diperkuat dengan $\mathrm{p}$ value $<$ Sig. 0,05 atau $(2,011>0,05)$ Dengan demikian maka H0 diterima dan H1 ditolak, hal ini menunjukan bahwa tidak terdapat pengaruh positif dan signifikan secara parsial antara Kompensasi terhadap Kinerja Karyawan pada PT Putra Abadi Jaya Mandiri Tangerang Selatan. Hasil ini sejalan dengan penelitian yang dilakukan oleh

Tabel 17. Hasil analisis koefisien determinan secara parsial antara kompensasi (X1)

Terhadap kinerja karyawan (Y)

\begin{tabular}{|c|c|c|c|c|}
\hline \multicolumn{5}{|c|}{ Model Sumery } \\
\hline Model & $\mathbf{R}$ & R Square & $\begin{array}{c}\text { Adjusted R } \\
\text { Square }\end{array}$ & Std. Error of the Estimate \\
\hline 1 &, $163^{\mathrm{a}}$ & ,027 & ,006 & 3,47691 \\
\hline Predi & s: (Cons & Kompensasi & & \\
\hline
\end{tabular}

Sumber: Data primer diolah

Tabel 18. Hasil analisis koefisien determinan secara parsial antara motivasi (X2)

Terhadap kinerja karyawan (Y)

\begin{tabular}{lllll}
\hline & \multicolumn{4}{c}{ Model Sumery } \\
\hline Model & R & R Square & $\begin{array}{c}\text { Adjusted R } \\
\text { Square }\end{array}$ & Std. Error of the Estimate \\
\hline 1 &, $620^{\text {a }}$ &, 384 &, 371 & 2,76581 \\
\hline
\end{tabular}

a. Predictors: (Constant), Motivasi

Sumber: Data primer diolah

Tabel 19. Hasil analisis koefisien determinan secara simultan antara variabel kompensasi (X1) dan motivasi (X2) terhadap kinerja karyawan (Y)

\begin{tabular}{|c|c|c|c|c|}
\hline \multicolumn{5}{|c|}{ Model Sumery } \\
\hline Model & $\mathbf{R}$ & R Square & $\begin{array}{c}\text { Adjusted R } \\
\text { Square }\end{array}$ & Std. Error of the Estimate \\
\hline 1 & ,654 ${ }^{\mathrm{a}}$ & ,428 & ,404 & 2,69339 \\
\hline Pre & ors: $(\mathrm{Cc}$ & t), Motivasi (X2 & mpensasi (X1) & \\
\hline
\end{tabular}

Sumber: Output SPSS yang diolah, 2020 
(Mundakir \& Zainuri, 2018) yang mengatakan bahwa kompensasi tidak berpengaruh terhadap kinerja PNS (Pegawai Negeri Sipil ) pada Kantor Dinas Pekerjaan Umum Kabupaten Rembang.

Berdasarkan pada hasil pengujian pada tabel 21 diperoleh nilai $\mathrm{t}$ hitung $>\mathrm{t}$ tabel atau $(5,470>2,011)$. Hal tersebut juga diperkuat dengan nilai Pvalue <Sig. 0,05 atau $(2,011>0,05)$. Dengan demikian maka $\mathrm{H} 0$ ditolak dan $\mathrm{H} 2$ diterima, hal ini menunjukan bahwa terdapat pengaruh positif dan signifikan secara parsial antara motivasi kerja terhadap kinerja karyawan pada PT Putra Abadi Jaya Mandiri Tangerang Selatan. Hal ini sejalan dengan penelitian yang dilakukan oleh (Arisanti et al., 2019) yang mengatakan bahwa motivasi berpengaruh terhadap kinerja PT Pegadaian
(Persero) Cabang Nganjuk.

\section{Pengujian Hipotesis Secara Simultan (Uji F)}

Berdasarkan pada hasil pengujian pada tabel 22 diperoleh nilai $\mathrm{F}$ hitung $<\mathrm{F}$ tabel atau $(1,308<2,800)$, hal ini juga diperkuat dengan $\mathrm{p}$ value $>$ Sig. 0,05 atau $(0,000<0,05)$. Dengan demikian maka H0 diterima dan $\mathrm{H} 3$ ditolak, hal ini menunjukan bahwa tidak terdapat pengaruh positif dan signifikan secara simultan antara Kompensasi dan Motivasi terhadap Kinerja Karyawan pada PT Putra Abadi Jaya Mandiri Tangerang Selatan. Hal ini sejalan dengan penelitian yang dilakukan oleh (Suwati, 2013) yang mengatakan bahwa pemberian kompensasi dan motivasi tidak berpengaruh terhadap kinerja karyawan PT Tunas Hijau Samarinda.

Tabel 20. Hasil uji hipotesis (Uji t) variabel kompensasi (X1) terhadap kinerja karyawan (Y)

Coefficients $^{\mathrm{a}}$

\begin{tabular}{|c|c|c|c|c|c|}
\hline & \multicolumn{2}{|c|}{$\begin{array}{l}\text { Unstandardizzed } \\
\text { Coefficients }\end{array}$} & \multirow{2}{*}{$\begin{array}{c}\text { Standarsized } \\
\text { Coefficients } \\
\text { Beta }\end{array}$} & & \\
\hline & B & Std. Error & & & \\
\hline (Constant) & 35,608 & 3,629 & & 9,812 & .000 \\
\hline Kompensasi (X1) &, 110 & .096 & .163 & 1,144 & ,258 \\
\hline
\end{tabular}

Sumber: Data primer diolah

Tabel 21. Hasil uji t variabel motivasi (X2) terhadap kinerja karyawan (Y)

Coefficients $^{\mathrm{a}}$

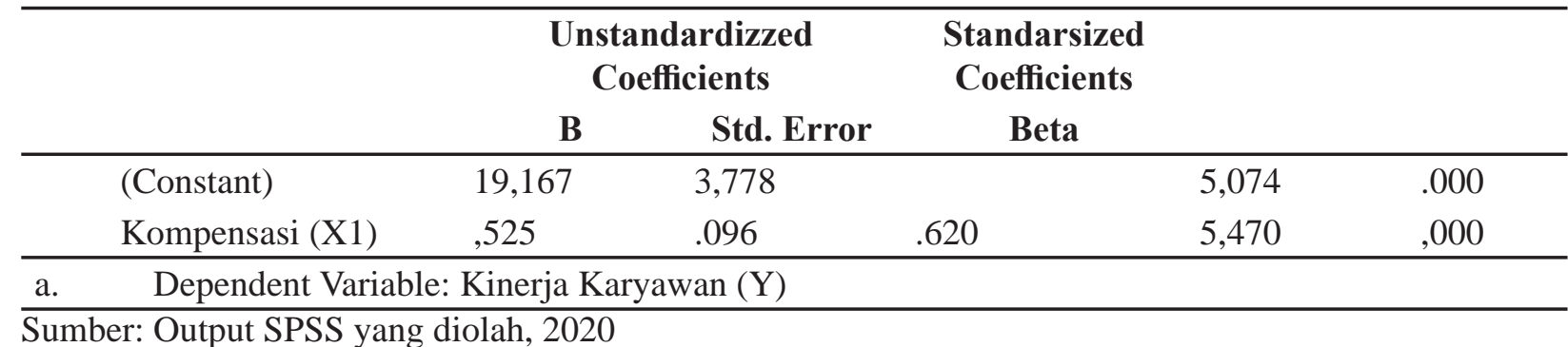

Tabel 22. Hasil hipotesis (uji F) secara simultan antara kompensasi (X1) dan motivasi (X2) terhadap kinerja karyawan (Y)

\begin{tabular}{llllccc}
\hline \multicolumn{1}{c}{ Model } & Sum of Square & Df & Mean Square & F & Sig. \\
\hline Regression & 15,812 & 1 & & 15,812 & 1,308 &, $258 \mathrm{~b}$ \\
Residual & 580,268 & 48 & 12,089 & & \\
Total & 596,080 & 49 & & & \\
\hline
\end{tabular}

Sumber: Output SPSS yang diolah, 2020 


\section{SIMPULAN}

Berdasarkan hasil penelitian yang telah dilakukan dapat ditarik kesimpulan bahwa Kompensasi (X1) tidak berpengaruh positif dan signifikan terhadap kinerja karyawan sebesar 2,7\%. Dari pengujian hipotesis diperoleh thitung $>\mathrm{t}$ tabel atau $(1,144>2,011)$ hal ini diperkuat dengan signifikansi $\mathrm{P}$ value $<$ Sig. 0,05 atau 0,000 $<0,05$, dengan demikian maka H0 diterima dan $\mathrm{H} 1$ ditolak, artinya tidak terdapat pengaruh positif dan signifikan secara parsial antara kompensasi dengan kinerja karyawan. Motivasi berpengaruh positif dan signifikan terhadap kinerja karyawan sebesar $38,4 \%$. Dari pengujian hipotesis diperoleh $\mathrm{t}$ hitung $>\mathrm{t}$ tabel atau $(5,470>2,011)$. Hal ini diperkuat dengan signifikansi $\mathrm{P}$ value $<$ Sig. 0,05 atau $0,000<0,05$, dengan demikian maka H0 ditolak $\mathrm{H} 2$ diterima, artinya terdapat pengaruh positif dan signifikan secara parsial antara motivasi terhadap kinerja karyawan. Kontribusi pengaruh kompensai dan motivasi secara simultan adalah sebesar $42,8 \%$. Sedangkan sisanya sebesar $57,2 \%$ dipengaruhi oleh factor lain. Dari pengujian hipotesis menggunakan uji statistic $\mathrm{F}$ hitung $>\mathrm{F}$ tabel atau $(1,308<2,800)$, hal tersebut juga diperkuat dengan signifikansi $(0,000<0,05)$. Dengan demikian H0 ditolah H3 diterima. Artinya tidak terdapat pengaruh positif dan signifikan secara simultan antara kompensasi dan motivasi terhadap kinerja karyawan.

\section{PENGHARGAAN}

Pada kesempatan kali ini penulis ingin mengucapkan terimakasih kepada semua yang terlibat baik secara langsung maupun tidak langsung yang tidak bisa penulis sebutkan satu persatu. Terimakasih atas saran, masukan, dan bantuan, semoga penelitian ini bisa bermanfaat bagi semua pihak.

\section{DAFTAR PUSTAKA}

Arisanti, K. D., Santoso, A., \& Wahyuni, S. (2019). Pengaruh Motivasi Kerja Dan Disiplin Kerja Terhadap Kinerja Karyawan Pada PT Pegadaian (Persero) Cabang Nganjuk. JIMEK : Jurnal Ilmiah Mahasiswa Ekonomi, 2(1), 101. https://doi.org/10.30737/jimek. v2i1.427

Diansyah, M., Athar, H. S., \& Fauzi, A. (2020). Kompetensi Dan Komitmen Organisasi Kaitanya Pada Motivasi Dan Kinerja Pegawai. Jurnal Distribusi, 8(2), 267-276.

Dwianto, A. S., Purnamasari, P., \& Tukini, T. (2019). Pengaruh Kompensasi Terhadap Kinerja Karyawan Pada PT. JAEIL INDONESIA. Jesya (Jurnal Ekonomi Dan Ekonomi Syariah), 2(2), 209-223.

Fadhil, A., \& Mayowan, Y. (2018). Pengaruh motivasi kerja dan kepuasan kerja terhadap kinerja karyawan AJB Bumiputera. Jurnal Administrasi Bisnis, 54(1), 40-47.

Hasibuan, S.P, M. (2016). Manajemen Sumber Daya Manusia (Edisi Revisi). PT Bumi Aksara.

Hasibuan, D. (2019). Pengaruh Kompensasi dan Kompetensi terhadap Kinerja Karyawan PT. Herfinta Aek Batu Kecamatan Torgamba Kabupaten Labuhanbatu Selatan. ECOBISMA (Jurnal Ekonomi, Bisnis Dan Manajemen), 6(1), 9-15.

Hidayati, U. (2020). Manajemen Sumber Daya Manusia (Nurfitriani (ed.)). Cendekia Publisher.

Komara Eka Putri, M. A., \& Basri, H. (2014). Pengaruh Penerapan E-Kinerja Dan Penghargaan (Reward) Terhadap Kinerja Aparatur Pengelolaan Keuangan Di Lingkungan Pemerintahan Kota Banda Aceh. Jurnal Administrasi Akuntansi: Program Pascasarjana Unsyiah, 3(4).

Mulyadi \& Setiawan, J. (2007). Sistem Perencanaan Dan Pengendalian Manajemen: Sistem Pelipatgandaan Kinerja Perusahaan. Jakarta.

Mundakir, M., \& Zainuri, M. (2018). Pengaruh Kompensasi dan Motivasi terhadap Kinerja Pegawai Negeri Sipil dengan Kepuasan Kerja sebagai Variabel Intervening. Business Management Analysis Journal (BMAJ), 1(1), 26-36.

Rialmi, Z., Asmalah, L., \& Fatimah, S. (2020). Pengaruh Gaya Kepemimpinan terhadap Kinerja Pekerja PT Jaya Inter Supra. Jurnal Madani: Ilmu Pengetahuan, Teknologi, 
Dan Humaniora, 3(1), 83-94. https://doi. org/10.33753/madani.v3i1.82

Silaen, N. R., Syamsuriansyah, S., Chairunnisah, R., Sari, M. R., Mahriani, E., Tanjung, R., Triwardhani, D., Haerany, A., Masyruroh, A., Satriawan, D. G., Lestari, A. S. I., Arifudin, O., Rialmi, Z., \& Putra, S. (2021). KINERJA KARYAWAN. In Widina Bhakti Persada Bandung. Widina Bhakti Persada Bandung.

Sugiyono, M. P. P., \& Kuantitatif, P. (2009). Kualitatif, dan R\&D, Bandung: Alfabeta. Cet. Vii.

Sutedjo, A. S., \& Mangkunegara, A. P. (2018). Pengaruh Kompetensi dan Motivasi Kerja terhadap Kinerja Karyawan di PT. Inti Kebun Sejahtera. BISMA (Bisnis Dan Manajemen), 5(2), 120-129.

Suwati, Y. (2013). Pengaruh kompensasi dan motivasi kerja terhadap kinerja karyawan pada PT. Tunas Hijau Samarinda. Jurnal Ilmu Administrasi Bisnis, 1(1), 41-55.

Suwatno, H. d, \& Priansa, D. J. (2014). Manajemen SDM dalam organisasi Publik dan Bisnis.

Syafaruddin. (2015). Manajemen Organisasi Pendidikan: Perspektif Sains dan Islam (Ch. Wijaya \& Mesiono (eds.); Pertama). Perdana Publishing. 